\title{
Electropolymerization of Electroinactive Polypyrrole Film for a Nonlinear MIM Switching Device
}

\author{
Tetsuya OSAKA*, Toshihiro FUKUDA, Kiyoshi OUCHI \\ and Toshiki NAKAJIMA ${ }^{\dagger}$
}

Received June 13, 1991; Accepted August 22, 1991

\begin{abstract}
Thin films of electroinactive polypyrrole (PPy) were electropolymerized in NaOH aqueous solutions on ITO (indium tin oxide) electrodes for the purpose of constructing nonlinear MIM (metal-insulator-metal) switching devices for large scale flat panel displays. Electroactivity and morphology of PPy films were greatly affected by the $\mathrm{NaOH}$ concentration. Highly anodic potential $(1.5 \mathrm{~V}$ vs. $\mathrm{Ag} / \mathrm{AgCl})$ electrolysis in $\mathrm{NaOH}$ solution produced carbonyl groups in the PPy chain, so that electroinactive PPy was nonconducting in as-prepared conditions. The MIM structure of ITO/PPy/ITO was fabricated by ITO sputtering onto the PPy film. The device using the PPy film prepared from $0.01 \mathrm{~mol} \mathrm{dm}^{-3} \mathrm{NaOH}$ aqueous solution showed nonlinear and symmetric current-voltage $(\mathrm{I}-\mathrm{V})$ characteristics. In spite of using the nonconductive PPy, a dependence of $I-V$ characteristics on polymerization time was observed, and a proper polymerization time was required to produce an MIM device.
\end{abstract}

\section{INTRODUCTION}

Electropolymerized films are insensitive to air. They are able to be prepared highly conductng, semiconducting and insulating materials when varying their polymerized conditions. Highly conducting or semiconducting polymers, formed by electropolymerization, have been extensively investigated from a practical point of view for electronic device application. Indeed, Schottky junction-type diodes ${ }^{1)}$ and field-effect transistors (FETs) ${ }^{2)}$ have been demonstrated using, e.g., a copolymer of pyrrole and $\mathrm{N}$-methylpyrrole units, and polythiophene respectively. An application of electroinactive or nonconducting polymers formed with a electropolymerization technique, however, has scarcely been tried in this field. We have fabricated an MIM (metal-insulatormetal) device using an electropolymerized nonconducting film as an insulator ${ }^{3,4)}$.

The MTM device is a nonlinear, two terminal device, and its structure is simpler than that

Department of Applied Chemistry, School of Science and Engineering, Waseda University (3-4-1 Okubo, Shinjuku-ku, Tokyo 168)

+SEIKO EPSON Co. (17-1 Tsukahara 1-Chome, Chino-shi, Nagano 391)

Key Words: Electroinactive polypyrrole, Highly anodic electrolysis, Nucleophilic hydroxide ion, Nonlinear MIM device of a TFT (thin film transistor). An application of it to the switching element for the multiplexed liquid crystal (LC) display is expected5). The insulator of the MIM switching device is practically used with a $\mathrm{Ta}_{2} \mathrm{O}_{5}$ layer formed by anodizing a sputtered $\mathrm{Ta}$ film. Its fabricating process is still complex, and a simplified fabricating-process is required in order to realize a large area LC panel. On the basis of this requirement, some insulating organic films, such as polyimide formed using a Langmuir-Blodgett method ${ }^{6}$, polyfuran using plasma polymerization?, and polyethylene using an evaporated method $\left.{ }^{8}\right)$ have been reported. We have already reported an MIM device using undoped poly-N-methylpyrrole (PMPy) film as an insulator ${ }^{3}$ ). An electropolymerization method is highly suitable for larger area fabrication, but the undoped PMPy film reported in ref. 3 is very sensitive to its anion undoping process, so that the stability of electric characteristics of this element must be developed.

In this paper, we try to use directly formed nonconducting polypyrrole (PPy) as an insulator ${ }^{4}$, instead of undoped polymers, and report and discuss the nonlinear properties of the MIM device using the electroinactive PPy insulator. 


\section{EXPERIMENTAL}

2.1 Chemicals and solutions

Reagent grade pyrrole (Tokyo Kasei Co.,Ltd.), NaClO4 (Kanto Chemical Co., Inc.) and $\mathrm{NaOH}$ (Kokusan Chemical Works Ltd.) were used without further purification. Photoresists OMR-83 and OFPR-800 (Tokyo Ohka Kogyo Co., Ltd.) were used for ITO (indium tin oxide) glass substrate preparation and for etching the upper ITO electrode respectively. Aqueous solutions containing $0.25 \mathrm{~mol} \mathrm{dm}^{-3}$ pyrrole monomer and $0.05,0.01$, and $0.001 \mathrm{~mol} \mathrm{dm}^{-3}$ $\mathrm{NaOH}$ electrolyte salts were used for the preparation of PPy films. They were deaerated by argon gas before use.

\section{2. $2 \mathrm{Film}$ preparation and electrochemical} measurements

For the electropolymerization and electrochemical measurements, the cell was assembled with an ITO working electrode, a Pt counter electrode, and an $\mathrm{Ag} / \mathrm{AgCl}$ reference electrode. Cyclic voltammetry at $10 \mathrm{mV} \mathrm{s}^{-1}$ was employed for surveying both electropolymerization behavior and the redox process. PPy films were formed by constant potential electrolysis at 1.5 $\mathrm{V}$ vs. Ag/AgCl with varying electrolysis time. Electroactive PPy for Fourier-transformed infrared (FT-IR) and visible (Vis) spectroscopic measurements were formed by constant potential electrolysis at $0.65 \mathrm{~V}$ vs. $\mathrm{Ag} / \mathrm{AgCl}$ from an aqueous solution containing $0.2 \mathrm{~mol} \mathrm{dm}^{-3}$ pyrrole monomer and $0.1 \mathrm{~mol} \quad \mathrm{dm}^{-3} \quad \mathrm{NaClO}_{4}$ electrolyte salt.

2.3 Fabrication and current-voltage ( $I-V$ ) characteristics measurement of an MIM device

Device fabrication was performed as previously reported ${ }^{3,4)}$. A schematic representation of the MIM device is shown in Fig. 1. The holes for deposited polypyrrole layer were prepared on the ITO (ca. $400 \mathrm{~nm}$ thick) glass substrate using a photolithographic technique. The hole sizes were 100, 300, 500, 700, $1000 \mathrm{jm}$ in diameter. PPy films formed by constant potential electrolysis at $1.5 \mathrm{~V}$ vs. $\mathrm{Ag} / \mathrm{AgCl}$ were used for fabrication of the device. After a

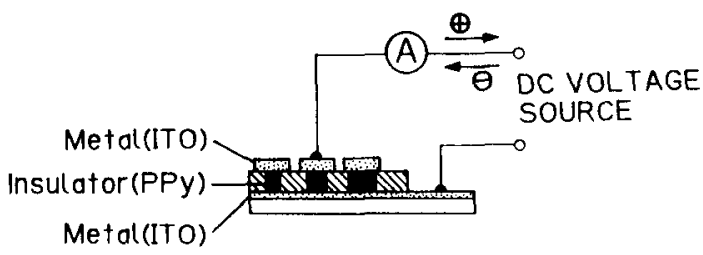

Fig. 1. Schematic representation of the MIM device structure. rinse in water and drying by a stream of argon gas of the PPy coated electrode, the upper ITO electrodes (ca. $60 \mathrm{~nm}$ thick) were prepared by using sputtering and etching technique. I-V characteristics of the device were measured between $\pm 10 \mathrm{~V}$ by $0.5 \mathrm{~V}$ steps in the dark.

\subsection{Apparatus}

The microscopic FT-IR spectroscopic measurement was carried out by a JEOL JIR-5500. Vis spectra were recorded on a HITACHI U-3200 spectrophotometer. The morphology of PPy films was observed with a JEOL JSM-T20 scanning electron microscope (SEM). Film thickness was measured using a contact profile meter (Alpha-step 200 TENCOR INSTRUMENTS). For the film preparation, the Potentio/galvanostat HA-301 (Hokuto Denko Co., Ltd) was employed. I-V characteristics were measured using a YOKOGAWA HEWLETT-PACKARD $4140 \mathrm{~B}$ pA meter / dc voltage source.

\section{RESULTS and DISCUSSION}

3. 1 Selection of the polymerization solution Electropolymerization of insulating PPy has already been reported briefly by Murthy et al.9), but details of the polymerization condition have scarcely been described. We prepared three polymerization solutions containing $0.001,0.01$, and $0.05 \mathrm{~mol} \mathrm{dm}^{-3} \mathrm{NaOH}$, and surveyed electropolymerization behavior and the redox process of PPy films with cyclic voltammetry in polymerization solutions. Cyclic voltammograms over the range between $-0.3 \mathrm{~V}$ and $1.8 \mathrm{~V}$ vs. $\mathrm{Ag} / \mathrm{AgCl}$ for each solution are shown in Fig. 2. For the lower $\mathrm{NaOH}$ concentration (Fig. 2-(a)), anodic current for polymerization is shown at the first cycle and then the redox process is observed. This means that the PPy film obtained in $0.001 \mathrm{~mol} \mathrm{dm}^{-3}$ $\mathrm{NaOH}$ solution is somewhat electroactive and its conductivity is not very low. The PPy film formed from this polymerization solution is considered to be unsuitable for use in an MIM device. On the other hand, anodic currents for polymerization are also observed in both Figs. 2-(b) and 2-(c), however, the redox process is not shown. This indicates that PPy films obtained from these solutions are electroinactive and the conductivities are very low. For polyaniline ${ }^{10}$ ) and polyphenol11), it was reported that the electroinactive and low conducting films are obtained in high $\mathrm{pH}$ solutions. But $\mathrm{Li}$ et al. reported that, even in $\mathrm{NaOH}$ electrolyte solution, electroactive PPy film showed the redox process with a decrease in 


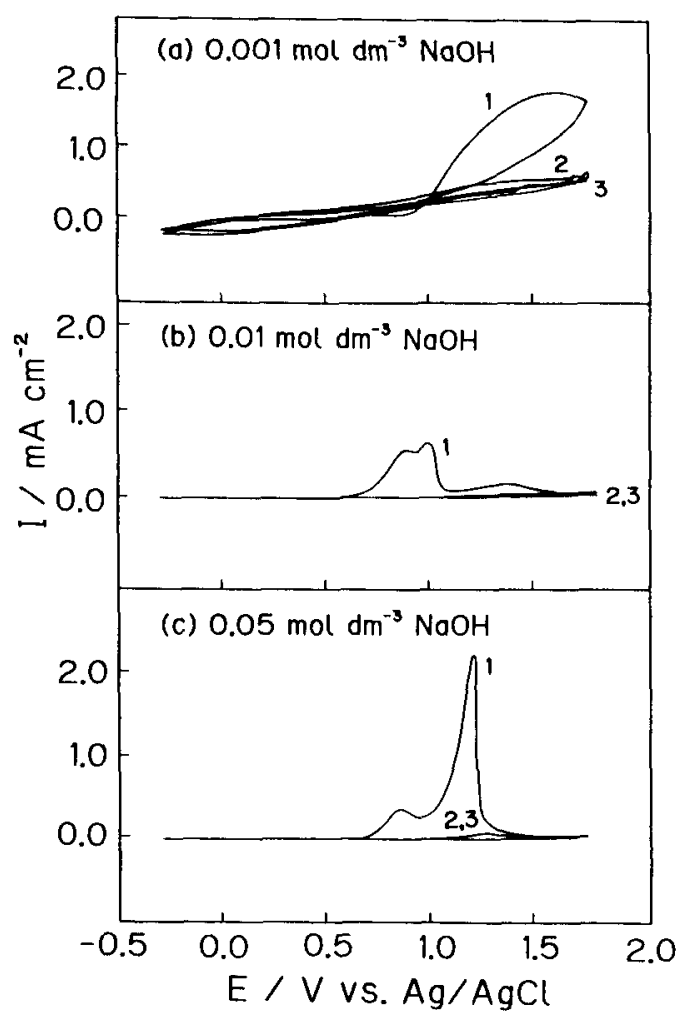

Fig. 2. Cyclic voltammograms at $10 \mathrm{mV} \mathrm{s}^{-1}$ in various $\mathrm{NaOH}$ aqueous solutions containing 0.25 mol dm-3 pyrrole: (a) $0.001 \mathrm{~mol} \mathrm{dm}^{-3}$, (b) 0.01 $\mathrm{mol} \mathrm{dm}$, and (c) $0.05 \mathrm{~mol} \mathrm{dm}^{-3} \mathrm{NaOH}$. Figures indicate the cycle numbers.

conductivity when an adequate scan range was selected, and that it became electroinactive when the anodic scan went to a higher anodic potential12). Judging from these reports, the electroinactivity of the PPy films obtained from 0.01 and $0.05 \mathrm{~mol} \mathrm{dm}^{-3} \mathrm{NaOH}$ solution is considered to be affected by highly anodic potential electrolysis rather than high $\mathrm{pH}$ value. Highly anodic potential ( $1.5 \mathrm{~V}$ vs. $\mathrm{Ag} / \mathrm{AgCl}$ ) electrolysis was employed for film preparation.

Next, we tried to electropolymerize PPy films for MIM devices in 0.01 and $0.05 \mathrm{~mol} \mathrm{\textrm {dm } ^ { - 3 }}$ $\mathrm{NaOH}$ polymerization solutions by constant potential electrolysis at $1.5 \mathrm{~V}$ vs. $\mathrm{Ag} / \mathrm{AgCl}$. The surface morphology, the film thickness and the adherence to the ITO electrode are considered to affect I-V characteristics of the device significantly. The surface morphology of electroinactive PPy films were observed and are shown in Fig. 3, indicating the SEM images of PPy films obtained from 0.01 and $0.05 \mathrm{~mol} \mathrm{am}$

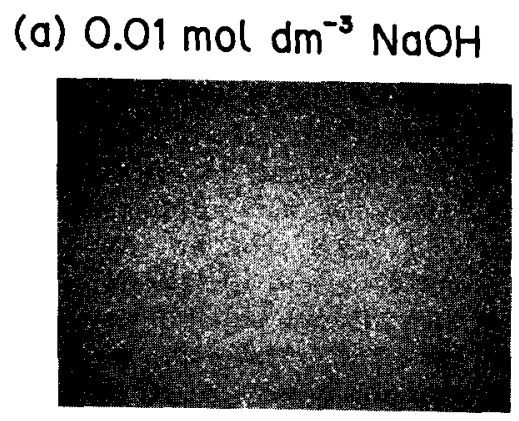

(b) $0.05 \mathrm{~mol} \mathrm{dm}-3 \mathrm{NaOH}$

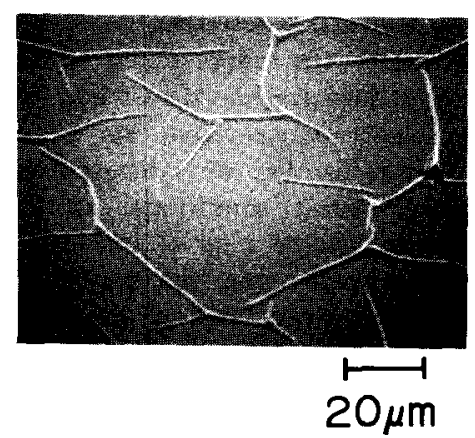

Fig. 3. SEM images of PPy films electropolymerized at $1.5 \mathrm{~V}$ vs. $\mathrm{Ag} / \mathrm{AgCl}$ from polymerization solutions (a) $0.01 \mathrm{~mol} \mathrm{dm}^{-3}$ and (b) $0.05 \mathrm{~mol} \mathrm{dm}^{-}$ $3 \mathrm{NaOH}$. Each solution contains $0.25 \mathrm{~mol} \mathrm{\textrm {dm } ^ { - 3 }}$ pyrrole.

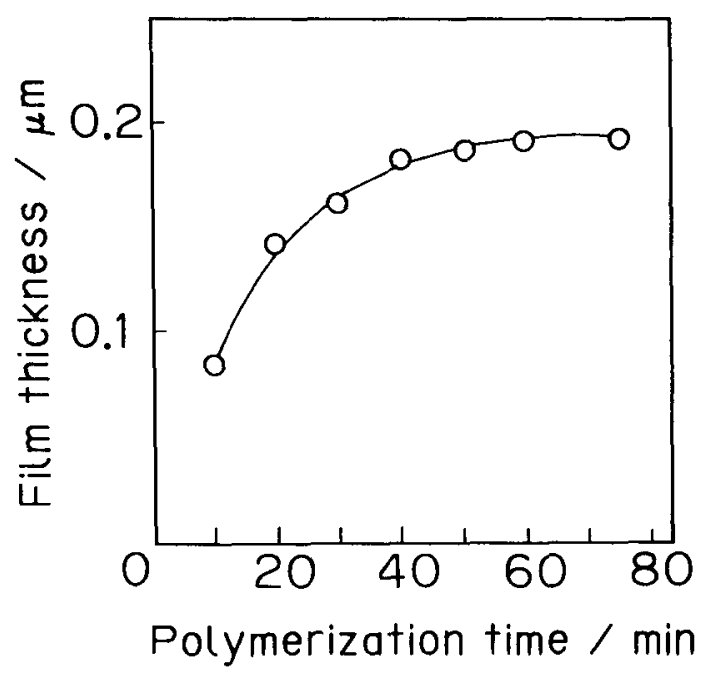

Fig. 4. The relationship between film thickness and electrolysis time at $1.5 \mathrm{~V}$ vs. $\mathrm{Ag} / \mathrm{AgCl}$ from $0.01 \mathrm{~mol} \mathrm{\textrm {dm } ^ { - 3 }} \mathrm{NaOH}$ polymerization solution containing $0.25 \mathrm{~mol} \mathrm{dm}^{-3}$ pyrrole. 
$\mathrm{NaOH}$ polymerization solutions. In Fig. 3-(a), the PPy film obtained from $0.01 \mathrm{~mol} \mathrm{dm}^{-3} \mathrm{NaOH}$ solution is thin (ca. $0.2 \mu \mathrm{m}$ thick) and very smooth, so it would be free of the pin-hole defects. On the other hand, in Fig. 3-(b), the PPy film from $0.05 \mathrm{~mol} \mathrm{dm}^{-3} \mathrm{NaOH}$ solution is thicker than that from $0.01 \mathrm{~mol} \mathrm{dm}^{-3} \mathrm{NaOH}$. However, wrinkles are observed, so the adherence of this film to the ITO electrode is found to be very low. Therefore, we selected the PPy film obtained from $0.01 \mathrm{~mol} \mathrm{dm}^{-3} \mathrm{NaOH}$ polymerization solution for an MIM device because of its low conductivity and good adherence to the ITO electrode.

Figure 4 shows the dependence of the film thickness on polymerization time when the PPy films were electropolymerized at $1.5 \mathrm{~V}$ vs. $\mathrm{Ag} / \mathrm{AgCl}$. Electroinactive PPy has low conductivity in as-prepared conditions, so the film thickness shows a rapid rate of increase at the start of polymerization and the deposition rate of the film slows down with a proceeding of deposition. The thickness of the PPy film is found to be saturated at ca. $0.2 \mu \mathrm{m}$.

\section{$3.2 \mathrm{Vis}$ and IR spectra}

The Vis spectra of electro-active and -inactive PPy films are shown in Fig. 5. Curve (a) in Fig. 5 shows the spectrum of the electroactive PPy film formed from polymerization solution containing $\mathrm{NaClO}_{4}$ as an electrolyte at 0.65 $\mathrm{V}$ vs. Ag/AgCl. The spectrum contains broad absorption of more than $600 \mathrm{~nm}$, originating from what is called the bipolaron absorption ${ }^{13)}$. But such a bipolaron absorption is not observed in the electroinactive PPy film formed from $0.01 \mathrm{~mol} \mathrm{dm}^{-3} \mathrm{NaOH}$ polymerization solution at $1.5 \mathrm{~V}$ vs. $\mathrm{Ag} / \mathrm{AgCl}$ for $60 \mathrm{~min}$ even in as-prepared conditions (curve (b)). Li et al. reported a similar spectrum in undoped and low conducting $P P y$ by in situ spectrum measurement12). These facts imply that the electroinactive PPy is not in a bipolaron state and also that it is very low conducting in asprepared conditions.

Figure 6 shows the FT-IR spectra of electro-active and -inactive PPy film species. Both in electro-active (curve(a)) and -inactive (curve(b)) PPy films, the absorption peaks assigned to pyrrole rings (ca. 860, 1017, 1162, 1524, and $3218 \mathrm{~cm}^{-1}$ ) are demonstrated. A strong absorption peak at $1697 \mathrm{~cm}^{-1}$ is clearly observed in curve (b), not so clear in curve (a). This peak can be attributed to the $\mathrm{C}=0$ stretching vibration, indicating that the carbonyl $(\mathrm{C}=0)$ groups exist in the electroinactive PPy chain. The carbonyl groups may be intro-

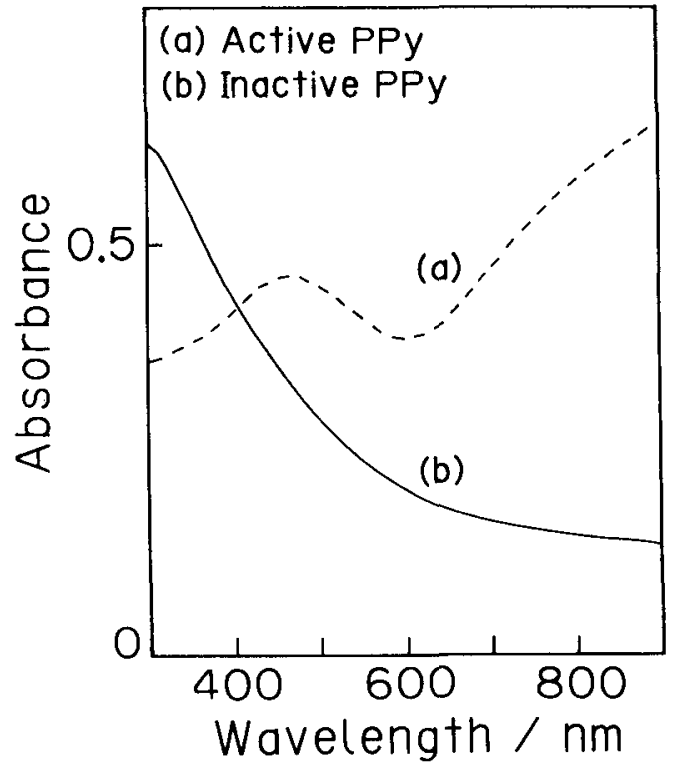

Fig. 5. Vis spectra of electro-active and -inactive PPy films: (a) electroactive PPy film formed at $0.65 \mathrm{~V}$ vs. $\mathrm{Ag} / \mathrm{AgCl}$ from an aqueous

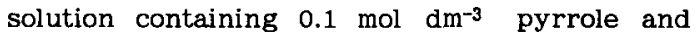
$0.2 \mathrm{~mol} \mathrm{dm}^{-3} \mathrm{NaClO}_{4}$, (b) electroinactive PPy film formed at $1.5 \mathrm{~V}$ vs. $\mathrm{Ag} / \mathrm{AgCl}$ for $60 \mathrm{~min}$ from an aqueous solution containing $0.25 \mathrm{~mol}$

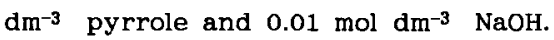

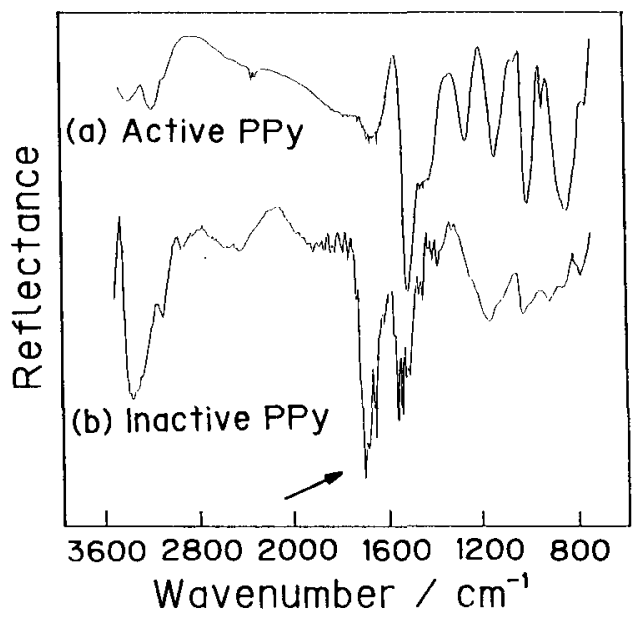

Fig. 6. FT-IR reflection spectra of electroactive and -inactive PPy films: (a) electroactive PPy film formed at $0.65 \mathrm{~V}$ vs. $\mathrm{Ag} / \mathrm{AgCl}$ from an aqueous solution containing $0.1 \mathrm{~mol} \mathrm{m^{-3 }}$

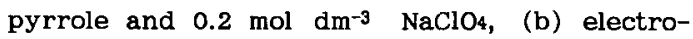
inactive PPy film formed at $1.5 \mathrm{~V}$ vs. $\mathrm{Ag} / \mathrm{AgCl}$ for $60 \mathrm{~min}$ from an aqueous solution containing $0.25 \mathrm{~mol} \mathrm{dm}^{-3}$ pyrrole and $0.01 \mathrm{~mol} \mathrm{dm}^{-3} \mathrm{NaOH}$. 
duced by highly anodic potential electrolysis (1.5 V vs. $\mathrm{Ag} / \mathrm{AgCl})$. The possibility of attacks of nucleophilic hydroxide anions from the $\mathrm{NaOH}$ electrolyte to $a-$ or $\beta$ - carbons is shown in scheme 1.

(a) Hydroxide ion attock at $\alpha$-carbon

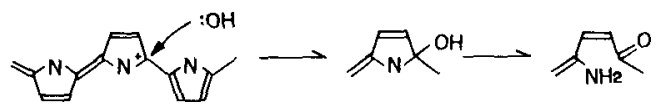

(b) Hydroxide ion attack at $\beta$-carbon

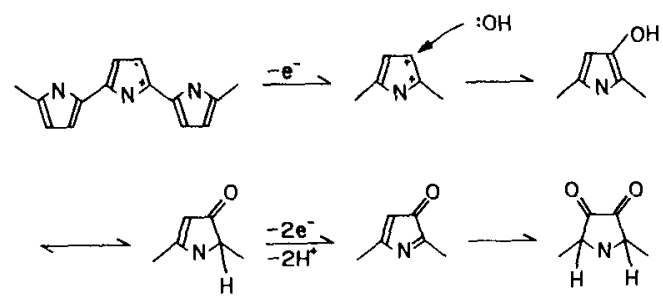

\section{Scheme 1}

The positive charged sites in PPy chain would exist in $\pi$-conjugated systems, so these two reactions shown in (a) and (b) are considered to occur simultaneously. Similar carbonyl group formation was reported as an irreversible overoxidation reaction which changed an electroactive polypyrrole ${ }^{14}$ or polythiophene
15) to an electroinactive and low conducting state. The nucleophilic reactions would occur at electrophilic sites of the positive charged bipolarons and lead to shortening of $\pi$-conjugated length of the PPy chain. Such reaction makes the PPy films electroinactive and low conducting in as-prepared conditions, and this film preparation method probably consists of both the polymerization and the irreversible overoxidation reaction.

\subsection{I-V characteristics of the MIM device}

Figure 7 shows $I-V$ characteristics of the MIM device using the PPy film formed from $0.01 \mathrm{~mol} \mathrm{dm}^{-3} \mathrm{NaOH}$ polymerization solution at $1.5 \mathrm{~V}$ vs. $\mathrm{Ag} / \mathrm{AgCl}$ for $60 \mathrm{~min}$. The positive and negative directions in Fig. 7-(a) and (b) correspond to a positive and negative bias in the ITO glass substrate respectively. The symmetric and nonlinear $I-V$ responses and increases in currents, ca. 5 orders of magnitude(Fig. 7-(a)), are reproducibly observed, and the switching behavior of threshold voltage at ca. $\pm 5 \mathrm{~V}$ is obtained as shown in Fig. 7-(b). A number of measurements also confirmed the stability of the electric properties of it. The hole size did not influence I-V characteristics. As for the reproducibility and no necessity of undoping process, this device is superior to that using the undoped PMPy film reported previously ${ }^{3)}$. Thus the electroinactive PPy films were found to be
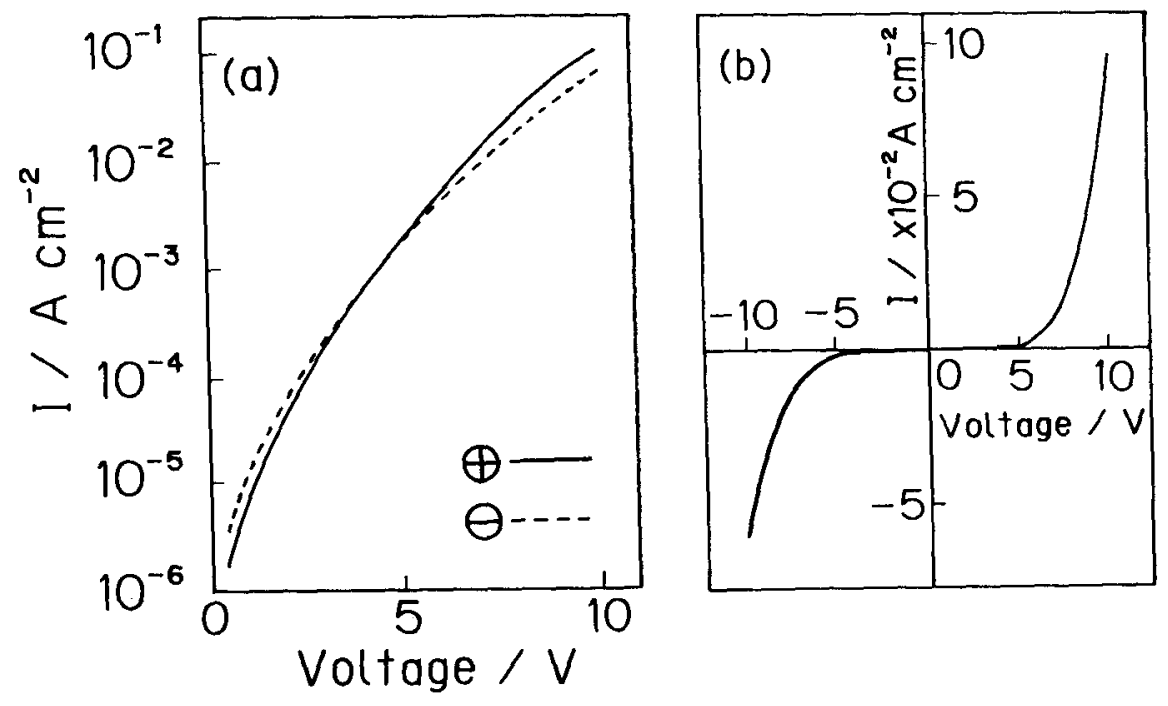

Fig. 7. I-V characteristics of the MIM device using the electroinactive PPy film formed at $1.5 \mathrm{~V}$ vs. $\mathrm{Ag} / \mathrm{AgCl}$ for $60 \mathrm{~min}$ from aqueous solution containing $0.25 \mathrm{~mol} \mathrm{dm}^{-3}$ pyrrole and $0.01 \mathrm{~mol}$ $\mathrm{dm}^{-3}$ NaOH: (a) $\log \mathrm{I}-\mathrm{V}$, (b) I-V. 
suitable for an insulator of the MIM device from a practical point of view.

Next, we tried to fabricate the devices with varying polymerization time. When polymerization time is shorter than $30 \mathrm{~min}$, high appliedvoltage caused the breakdown of the I-V characteristics. On the other hand, polymerization for more than 30min confirmed the stability of them. Figure 8 shows the typical I$V$ characteristics of the devices using PPy film deposited for 30 and $60 \mathrm{~min}$. The resistance and threshold voltages are found to increase with the passage of polymerization time. These phenomena can be explained as follows.

(1) An increase in the film thickness lowers the electric field of the PPy film, improving the resistance value.

(2) The structural change which improves the resistivity value proceeds during polymerization.

The former is easily confirmed by the results in Fig. 4. The latter is suggested by the relationship between PPy film conductivity and polymerization time. Figure 9 shows the relationship between polymerization time and the conductivity, 0.5 , of PPy films measured at currents of $+0.5 \mathrm{~V}$. The 0.5 value is found to clearly decrease with polymerization time. This is probably caused by the structural change of

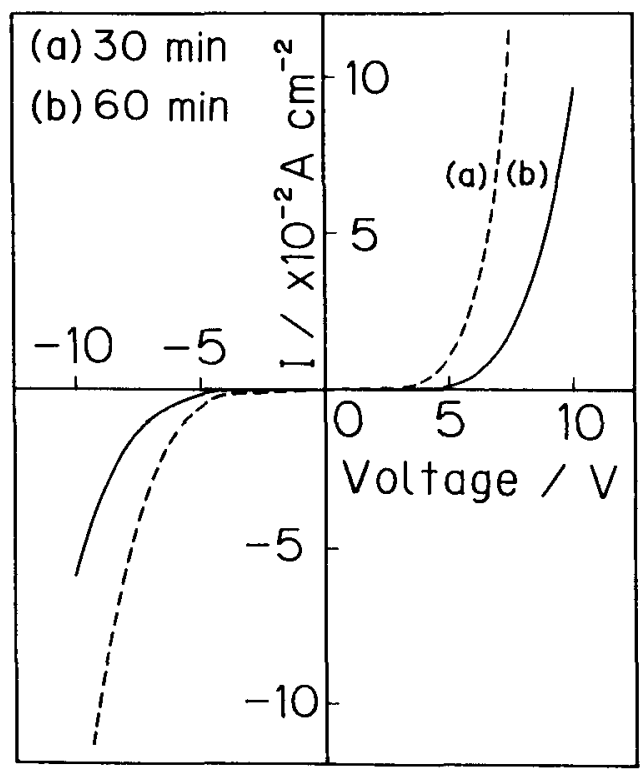

Fig. 8. I-V characteristics of the MIM device using PPy films deposited for (a) $30 \mathrm{~min}$ and (b) $60 \mathrm{~min}$. the PPy film. The Vis spectra of PPy films were measured with varying polymerization time. The Vis spectra of the PPy film of different polymerization time are shown in Fig. 10. With the passage of polymerization time, the bipolaron peak, which is slightly observed

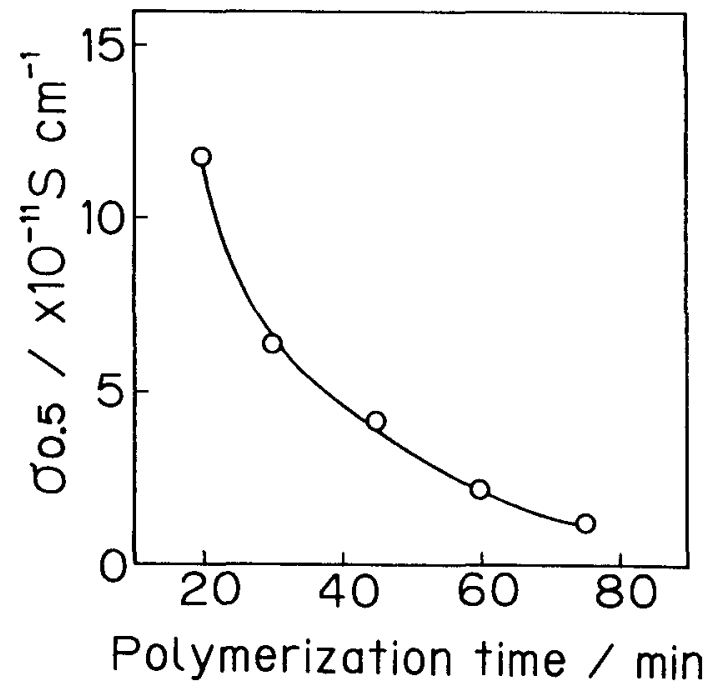

Fig. 9. The dependence of the conductivity, $0_{0.5}$, in electroinactive PPy films measured at $0.5 \mathrm{~V}$ on polymerization time.

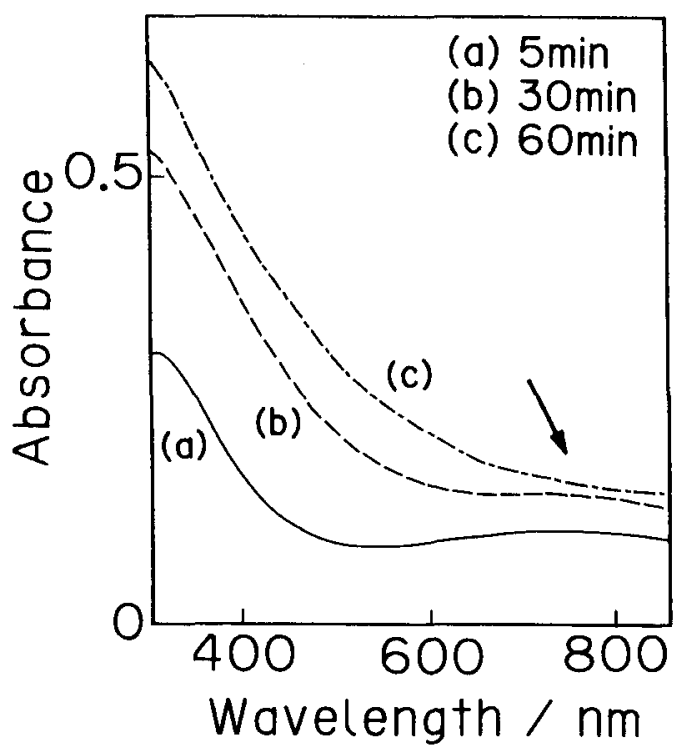

Fig. 10. Vis spectra of the PPy films as a function of polymerization time: (a) $5 \mathrm{~min}$, (b) $30 \mathrm{~min}$, (c) $60 \mathrm{~min}$. 
at $760 \mathrm{~nm}$, becomes smaller, and disappears completely at more than $45 \mathrm{~min}$ polymerization. This may be due to the attack of hydroxide anion to the positive site of the bipolaron leading to the destruction of it. Thus the improvement of the resistance value probably is due to both the increase of the film thickness and the proceeding overoxidation reaction.

\section{CONCLUSION}

The electroinactive and nonconducting PPy films were able to be electropolymerized from $\mathrm{NaOH}$ aqueous solution at highly anodic potential electrolysis. Their electroinactivity and less conductivity were for the most part caused by the overoxidation reaction. The concentration of $\mathrm{NaOH}$ affected not only the electroactivity but the morphology of the PPy film. The ITO/PPy/ITO type MIM device using the electroinactive PPy showed stable nonlinear $\mathrm{I}-\mathrm{V}$ responses, and the possibility of its practical use was demonstrated. The dependence of the I-V characteristics on polymerization time was explained by the increase in film thickness and structural changes of the PPy film.

The authors would like to acknowledge the experimental support and valuable discussion of Prof. Sadako NAKAMURA and Miss Keiko OIKE, Japan Women's University, and financial support from the Japanese Ministry of Education, Science and Culture.

\section{REFERENCES}

1) H. Koezuka and S. Etoh, J. Appl. Phys., 54, 2551 (1983).

2) H. Koezuka and A. Tsumura, Synth. Met., 28, C753 (1989).

3) T. Osaka, K. Ueyama, and K. Ouchi, Chem. Lett., 1989, 1543.

4) T. Osaka, K. Ouchi, and T. Fukuda, Chem. Lett., 1990, 1535.

5) D. E. Baraff, J. B. Long, C. J. Miner, and R. W. Streater, Conf. Record. of 1980 Biennial Display Resarch Conf., IEEE, 107, (1980).

6) H. Maeda, Y. Otobe, and S. Kobayashi, IEICEJ Tech. Rep., OME-89-43, 19, (1989).

7) P. K. Abraham, and K. Sathianandan, Thin Solid Films, 164, 353, (1988).

8) C. A. Hogarth, and M. Zor, phys. stat. sol. (a), 98, 611, (1986)

9) A. S. N. Murthy, and S. K. S. Reddy, J. Mater. Sci. Lett., 3, 745, (1984).

10) T. Ohsaka, Y. Ohnuki, and N. Oyama, J. Electroanal. Chem., 161, 399, (1984).

11) Y. Onnuki, H. Matsuda, T. Onsaka, and N.Oyama, J. Electroanal Chem., 158, 55, (1983).

12) Y. Li, and R. Qian, Synth. Met., 26, 139, (1989).

13) J. L. Bredas, J. C. Scott, K. Yakushi, and G. B. Street, Phys. Rev. B, 30, 1023, (1983).

14) F. Beck, P. Braun, and M. Oberst, Ber. Bunsenges. Phys. Chem., 61, 967, (1987).

15) S. Wang, K. Tanaka and T. Yamabe, Synth. Met., 32, 141, (1989). 